\title{
EL DERECHO A LA VERDAD: ¿̇LA EMERGENCIA DE UN NUEVO DERECHO EN LA JURISPRUDENCIA DEL TRIBUNAL EUROPEO DE DERECHOS HUMANOS?
}

\author{
"Right to truth": Emergence of a new right in the \\ case law of the European Court of Human Rights?
}

\author{
LUIS LÓPEZ GUERRA ${ }^{1}$ \\ lopez@der-pu.uc3m.es
}

Cómo citar/Citation

López Guerra, L. (2018).

El derecho a la verdad: ટ̇la emergencia de un nuevo derecho en la jurisprudencia del Tribunal Europeo de Derechos Humanos?

Anuario Iberoamericano de Justicia Constitucional, 22, 11-30. doi: https://doi.org/10.18042/cepc/aijc.22.01

\section{Resumen}

En la jurisprudencia del Tribunal Europeo de Derechos Humanos, el «derecho a la verdad» tiene una dimensión individual, en cuanto aparece como elemento integrante del aspecto procesal de los derechos del Convenio relativo a la obligación positiva de los Estados de realizar la adecuada investigación de las circunstancias de una violación de esos derechos a efectos de proporcionar una adecuada reparación a las víctimas. El Tribunal también ha reconocido el interés del público en general de que se realice esa investigación, pero sin que ese interés se traduzca en un derecho autónomo y diferenciado. En todo caso, la jurisprudencia del Tribunal admite que el derecho a informar y ser informado del art. 10 del Convenio supone la obligación de los Estados de proveer la información de que dispongan en materias de interés general, incluyendo violaciones graves de derechos humanos.

1 Catedrático de Derecho Constitucional. Exjuez del Tribunal Europeo de Derrechos Humanos. 


\section{Palabras clave}

Derecho a la verdad; obligaciones positivas; derecho a la información; Convenio Europeo de Derechos Humanos.

\section{Abstract}

In the case law of the European Court of Human Rights the "right to truth" has an individual dimension, as it appears as integrated into the procedural aspect of Convention rights. It refers to the States' positive obligation to perform an adequate investigation on the circumstances of the allegued violation of these rights, in order to provide a reparation to the victims. The Court has recognized the general interest of the public to an effective investigation of these violations, but this interest does not coinstitute an independent and autonomous right. In any case, the Court's case law admits that from the right to inform and being informed derived from Convention article 10 results the obligation of the States to provide, for the general knowledge, the information they have on matters of general interest, including grave violations of human rights.

\section{Keywords}

Right to truth; positive obligations; right to information; European Convention on Human Rights. 


\section{SUMARIO}

I. DIMENSIONES INDIVIDUAL Y COLECTIVA DEL DERECHO A LA VERDAD. II. LA DIMENSIÓN INDIVIDUAL DEL DERECHO A LA VERDAD: DERECHOS A LA VIDA Y A LA INTEGRIDAD FÍSICA. III. DERECHO A UNA INVESTIGACIÓN EN SUPUESTOS DE DESAPARICIONES. IV. LA DIMENSIÓN COLECTIVA DEL «DERECHO A LA VERDAD». V. LOS PROBLEMAS DE UNA EXTENSIÓN «COLECTIVA» DEL DERECHO A LA VERDAD. VI. ¿̇UN DERECHO COLECTIVO DE ACCESO A LA INFORMACIÓN? BIBLIOGRAFIA.

\section{DIMENSIONES INDIVIDUAL Y COLECTIVA DEL DERECHO A LA VERDAD}

En la literatura académica, en la legislación y en la jurisprudencia, la expresión «derecho a la verdad» se refiere al conocimiento de las circunstancias relativas a la vulneración de una serie de derechos fundamentales ${ }^{2}$; en la jurisprudencia tanto de la Corte Interamericana de Derechos Humanos como del Tribunal Europeo de Derechos Humanos, ese derecho versaría esencialmente sobre las vulneraciones de los derechos a la vida (art. 2 del CEDH, art. 4 de la Convención), a no sufrir torturas o tratos inhumanos o degradantes (art. 3 del CEDH, art. 5 de la Convención) o al derecho a no ser privado de libertad (art. 5 del CEDH, art. 7 de la Convención) .

La cuestión se ha planteado en ambos contextos, europeo y americano, con supuestos fácticos muy distintos, aun cuando pudiera ya decirse que ambos tribunales han adoptado líneas muy similares; en la presente exposición se hará referencia al caso europeo, que posiblemente haya tenido menor difusión (y quizá trascendencia) que la experiencia americana.

Como es bien sabido, la cuestión relativa a la existencia, extensión y titulares de un derecho a la verdad en el contexto americano se ha encontrado en gran parte vinculada a la transición entre regímenes autoritarios y regímenes constitucionales, y a la presencia de la llamada justicia transicional. Esta experiencia se extiende a países como Uruguay, Argentina, Bolivia, Brasil (y en cierta forma, en lo que se refiere a la existencia de

2 Para una exhaustiva visión general, Rodríguez (2017). 
una justicia transicional, Colombia) ${ }^{3}$. El paso de una situación de violación generalizada de los derechos humanos a una situación de normalidad constitucional ha dado lugar en estas situaciones a la exigencia de responsabilidad por las violaciones producidas, y correlativamente, a la exigencia de una exposición de los abusos realizados en este aspecto. En gran parte, las resoluciones de la Corte Interamericana han versado sobre obstáculos a estas pretensiones, por ejemplo, las leyes de amnistía o autoamnistía en ocasiones, que pretenden hacer lo que pudiera llamarse borrón y cuenta nueva respecto de esas violaciones, con las consecuencias de irresponsabilidad individual y desinformación colectiva. Ejemplos de sentencias de la Corte en este aspecto podría ser la bien conocidas Almonacid Arellano contra Chile, Gelman contra Uruguay o Barrios Altos contra Perú, para poner ejemplos que ya son clásicos.

El caso europeo es en gran manera distinto en lo que se refiere a la jurisprudencia del Tribunal Europeo de Derechos Humanos. Ciertamente, no han dejado de producirse en Europa transiciones de regímenes autoritarios poco respetuosos con los derechos humanos a regímenes con la pretensión de instaurar un sistema constitucional; y ello no solo en los bien conocidos casos de Europa Central y del Este, sino en contextos más cercanos, como el español. Pero aun cuando ciertamente se han producido en muchos de los países suscriptores del Convenio ese tipo de procesos de cambio, las decisiones del Tribunal no han versado, como regla general y con las excepciones que se verán, sobre cuestiones de justicia de transición, relativas a las responsabilidades incurridas por regímenes predemocráticos: las referencias a la obligación de establecer la verdad sobre vulneraciones de derechos se han referido a violaciones actuales de esos derechos, sin perjuicio de la dimensión individual o colectiva que quiera darse a esa obligación $n^{4}$.

Ahora bien, y pese a esas diferencias, una cuestión central con respecto a ese derecho a la verdad, en su aplicación hasta el momento tanto por la jurisprudencia del Tribunal de Estrasburgo como por la Corte Interamericana, es la que versa no tanto sobre su alcance como sobre todo sobre quiénes son sus titulares. Y ello tanto en un sentido sustantivo (quién ostenta ese derecho) como procesal (quién está legitimado para invocarlo en el curso de un proceso).

A este respecto, valga ya señalar la existencia inicial de dos perspectivas:

3 Sobre el caso de Colombia, con un proceso transicional de características propias (dentro de un sistema constitucional), véase De Prada Solaesa (2015).

4 Para un tratamiento de la jurisprudencia del Tribunal de Estrasburgo en esta materia, López Ulla (2013) y Chersinova (2016). 
a) Por un lado, una perspectiva que pudiéramos denominar individual, atribuyendo la titularidad y el ejercicio del «derecho a la verdad» a las víctimas de la violación de los derechos en cuestión, o bien a sus allegados y familiares más directos. El reconocimiento del derecho a la verdad estaría directamente vinculado a la reparación de vulneraciones de derechos fundamentales del Convenio a individuos concretos, mediante los correspondientes procesos ante los Tribunales, aplicando las reglas generales de legitimación procesal. Se trataría de un derecho de las víctimas.

b) Por otro lado, una perspectiva colectiva o pública. Yendo más allá de reclamaciones individuales, el derecho a la verdad aparecería como el derecho, por parte del público en general, a conocer la existencia de las violaciones en cuestión y sus circunstancias, aún por quienes no fueron víctimas directas de las mismas. El reconocimiento de esta dimensión colectiva tendría consecuencias también en el aspecto procesal, no solo en cuanto a los procedimientos para averiguar esas circunstancias, y los órganos encargados de esa averiguación, sino también en cuanto a la extensión de la legitimación al extender la legitimación para iniciar esos procedimientos, o participar en ellos, más allá del círculo de las víctimas directas de esas violaciones.

Una manifestación de esa dimensión colectiva del «derecho a la verdad» es la que se ha producido en varios países con ocasión de procesos de cambio de regímenes políticos dictatoriales a regímenes constitucionales, con la consecuente exigencia de publicidad y delimitación de responsabilidades derivadas de la vulneración de derechos fundamentales, no solo por vías judiciales sino también por vías no judiciales (por ejemplo, mediante la creación de «comisiones de la verdad» no jurisdiccionales) como un elemento más de la llamada justicia transicional ${ }^{5}$.

Valga señalar ya que en el caso europeo, quizá debido a esta relativa ausencia de casos de «justicia transicional» sometidos a las decisiones del Tribunal de Estrasburgo $^{6}$, este se ha centrado sobre todo en el primer aspecto señalado del derecho a la verdad — esto es, su dimensión individual, tanto sustantiva como procesal, como vía de reparación de la violación y compensación a las víctimas-. Pero no faltan muestras de una evolución que tiene en cuenta la dimensión colectiva, bien, aun manteniendo la atención en los derechos de las víctimas, como refuerzo de sus pretensiones, bien como un posible «derecho autónomo» con sujetos no identificados en todo caso con estas. Ello en virtud de un desarrollo no solo de la

5 Sobre este tema, Fornasari (2017) y Sweeney (2018).

6 Para una exposición inicial, Brems (2011). 
protección de los derechos sustantivos recogidos en los arts. 2, 3 y 5 del Convenio, sino también, y significativamente, en virtud del derecho a la libertad de expresión recogido en su art. 10. Como se indicó, ello ha llevado a posiciones cercanas a las del la Corte Interamericana de Derechos Humanos.

\section{LA DIMENSIÓN INDIVIDUAL DEL DERECHO A LA VERDAD: DERECHOS A LA VIDA Y A LA INTEGRIDAD FÍSICA}

Una versión inicial de las obligaciones de las autoridades nacionales de proporcionar un conocimiento veraz respecto de circunstancias de (alegadas) vulneraciones de los derechos del Convenio (sin que se emplee la expresión «derecho a la verdad») fue la derivada del concepto de «obligaciones positivas» de los Estados en relación con esos derechos. En expresión repetida, a partir de Marckx contra Bélgica del año 1979, el Tribunal de Estrasburgo ha partido de la base de que de los derechos del Convenio deriva no solo la obligación negativa de no actuar en su contra, sino también la de prevenir su posible violación, y, si esta se ha producido, llevar a cabo una averiguación suficiente al respecto para determinar las correspondientes responsabilidades y remediar o al menos paliar sus daños.

Este enfoque fue aplicado, en supuestos de alegada vulneración del derecho a la vida, en la sentencia en el caso McCann y otros contra Reino Unido, del año 1995, a raíz de la muerte, por fuerzas especiales británicas, de varios componentes de un grupo terrorista. El Tribunal, ante la demanda de familiares de las víctimas, halló una violación del art. 2, pero no respecto de las circunstancias de la muerte, sino debido a la falta de una suficiente investigación posterior en cuanto a tales circunstancias. El derecho a una investigación adecuada en casos de alegada vulneración del derecho a la vida o a la integridad física se configura, en McCann y jurisprudencia posterior, como un derecho autónomo, de tipo procesal incluso en casos en que no se hubiera producido una vulneración sustantiva del derecho. A lo largo de su jurisprudencia, el Tribunal ha ido perfilando las características que debe adoptar esa investigación, en supuestos de alegada vulneración de los derechos reconocidos en los arts. 2 y 3 del Convenio: debe ser pronta (para evitar la desaparición de pruebas con el paso del tiempo) por un órgano con la suficiente independencia, y, desde luego, contando con la presencia y participación de las víctimas o sus familiares y allegados directos ${ }^{7}$. La falta

7 Una enumeración de estos requisitos puede encontrarse, por ejemplo, en la sentencia en el caso Husayn (Abu Zubayda) contra Lituania (2018), par. 608. 
de esta investigación adecuada puede suponer que el Tribunal encuentre la presencia de dos violaciones simultáneas del art. 2 (o del 3 en otros supuestos): una violación sustantiva, derivada de la realidad de las circunstancias de la muerte o los malos tratos, y otra procesal, derivada de la ausencia de la necesaria investigación. Ello parte de la posible existencia de una vulneración adicional del derecho a un recurso o remedio adecuado (art. 13 del Convenio) frente a la alegada violación, debido a la ausencia legal, o a la falta de efectividad práctica de las vías procesales necesarias para ello.

Por otro lado, ha de destacarse que el Tribunal ha ido ampliando la legitimación para presentar demandas referentes a la vulneración del derecho a la vida y a la integridad física; por una lado, aparte de la víctima cuando ello fuera posible, por parte de los familiares y allegados directos (por ejemplo, en Orhan contra Turquía, del año 2002), pero además, y en algún caso, sin duda extremo, la legitimación de terceros, concretamente de organizaciones no gubernamentales. Tal fue el caso en Campeanu contra Rumanía, del año 2011. Como se verá, esta admisión de la legitimación de este tipo de organizaciones no deja de tener relevancia en cuanto a la posible admisión de un derecho a la verdad, al menos en algunos aspectos.

Esta jurisprudencia extiende la obligación de investigar a los supuestos de alegaciones de torturas o tratos inhumanos o degradantes del art. 3 del Convenio, y ello no solo imponiendo esa obligación a las autoridades competentes, sino también en cuanto que la inexistencia o insuficiencia de esa investigación puede suponer no solo una vulneración del aspecto procesal de los derechos en cuestión respecto de la víctima, sino también, respecto de sus familiares y allegados, un sufrimiento añadido constitutivo en sí mismo de una vulneración sustantiva del art. 3 del Convenio.

\section{DERECHO A UNA INVESTIGACIÓN EN SUPUESTOS DE DESAPARICIONES}

Esta exigencia de una investigación adecuada en supuestos de vulneración alegada del derecho a la vida ha tenido un desarrollo posterior en casos referentes a un supuesto específico, el relativo a las desapariciones forzadas de personas (en relación con la actividad de las autoridades). La jurisprudencia del Tribunal en estos casos, asimilando esa desaparición en determinadas circunstancias con una efectiva violación del derecho, tiene antecedentes (expresamente reconocidos por el Tribunal) tanto en disposiciones de derecho internacional como en la jurisprudencia de otras instancias internacionales. 
Con respecto a lo primero $^{8}$, y en referencia a hostilidades armadas, el art. 32 del Primer Protocolo Adicional a la Convención de Ginebra establece que «las actividades de las Altas Partes contratantes, de las Partes en conflicto y de las organizaciones humanitarias internacionales mencionadas en los Convenios y en el presente Protocolo deberán estar motivadas ante todo por el derecho que asiste a las familias de conocer la suerte de sus miembros». En una dimensión más amplia, el Convenio Internacional de Naciones Unidas para la protección de todas las personas frente a desapariciones forzadas (ICED, por sus siglas en inglés) establece en su art. 24:

2. Cada víctima tiene el derecho de conocer la verdad sobre las circunstancias de la desaparición forzada, la evolución y resultados de la investigación y la suerte de la persona desaparecida. Cada Estado Parte tomará las medidas adecuadas a este respecto.

3. Cada Estado Parte adoptará todas las medidas apropiadas para la búsqueda, localización y liberación de las personas desaparecidas y, en caso de fallecimiento, para la búsqueda, el respeto y la restitución de sus restos?.

Con respecto a lo segundo, esto es, los precedentes en otras instancias internacionales, el Tribunal de Estrasburgo hace expresa referencia en su jurisprudencia sobre desapariciones forzadas a la jurisprudencia al respecto del Tribunal Interamericano de Derechos Humanos y especialmente al conocido caso Velásquez Rodríguez contra Honduras, del año 1988, respecto a las responsabilidades de los Estados en supuestos de desapariciones forzadas ${ }^{10}$. El Tribunal de Estrasburgo tuvo oportunidad de pronunciarse sobre estos supuestos a partir de su sentencia en el caso Varnava contra Turquía, del año 2009. El Tribunal, en su jurisprudencia, considera la desaparición como un fenómeno caracterizado por una continua situación de incertidumbre y ausencia de responsabilidad en la que se produce una falta de información o una ocultación deliberada sobre lo que ha ocurrido (Ashlakanova y otros contra Rusia, 2012, párr. 100). La ausencia de información y la falta de explicaciones sobre la desaparición de una persona tras haberse encontrado bajo el control de las

8 Ver al respecto in extenso, Chersinova (2016).

9 En esta misma línea, cabe recordar la Resolución 68/185 de la Asamblea General de las Naciones Unidas sobre el Derecho a la Verdad, que efectúa un llamamiento a los Estados para que actúen en caso de violaciones graves de los derechos humanos, y establezcan vías para asegurar el respeto a esos derechos.

10 En general, sobre la jurisprudencia del Tribunal de Estrasburgo en esta materia, véase Keller y Chersinova (2012). 
autoridades conduce, por un lado, a una presunción de muerte de esa persona, trasladando a las autoridades la carga de la prueba de la no violación del art. 2, y por otro, a la constatación de una situación de angustia e incertidumbre de los familiares constitutiva de una violación del art. 3 del Convenio. En Varnava los hechos versaban sobre el destino de un conjunto de militares greco-chipriotas, con ocasión del enfrentamiento con el ejército turco; constatada la situación inicial de captura por las fuerzas turcas, la falta continuada de información sobre su situación y paradero condujo a la apreciación por el Tribunal de la violación de los arts. 2 (respecto de los desaparecidos) y 3 (respecto de los familiares de las víctimas).

La definición de las desapariciones como una situación continuada tiene consecuencias en cuanto al cálculo de los plazos para presentar la demanda ante el Tribunal; ello será posible siempre que esa situación de desaparición continuada sin la necesaria investigación se mantenga, esto es, no tomando como punto de referencia el momento de la constancia de la desaparición, sino dejando abierta la posibilidad del planteamiento de la demanda en tanto no se dé una explicación suficiente al respecto. Ello, sin embargo, de acuerdo con lo sentado en Varnava, no supone una prolongación indefinida de ese plazo, ya que los límites empezarán a computarse a partir del momento en que ya resulte evidente que las autoridades no van a llevar a cabo investigación alguna.

En general, debe señalarse que sobre la obligación de investigar en alegaciones relativas a los arts. 2 y 3 se ha planteado en alguna ocasión el alcance de la jurisdicción del Tribunal en aquellos casos en que los hechos se han producido con anterioridad a la entrada en vigor del Convenio respecto del país en cuestión (por ejemplo, en la sentencia en el caso Silih contra Eslovenia, del año 2009, o Janowiec contra Rusia, del año 2013, relativa a los desaparecidos durante el episodio de la Segunda Guerra Mundial conocido como «las fosas de Katyn»). Al tratarse la obligación de investigar de una obligación de procedimiento (esto es, de llevar a cabo las necesarias investigaciones), el Tribunal considera que puede desligarse del momento de realización de los hechos, al tratarse, como se apuntó, de una obligación autónoma, que se mantiene una vez el Convenio ha entrado en vigor, en el país, aun cuando los hechos fueran anteriores a esa entrada en vigor (Silih contra Eslovenia, 2009). Sin embargo, el Tribunal ha establecido también que no puede apreciarse una conexión entre los hechos originarios del caso, anteriores a la entrada en vigor del Convenio y la aplicación del mismo cuando tales hecho se produjeron con anterioridad a la misma adopción del Convenio el 4 de noviembre de 1950; pues solo entonces el Convenio se estableció como un tratado internacional. Ello independientemente de que diversos países condujeran 
actuaciones procesales contra violaciones de derechos humanos anteriores a esa fecha ${ }^{11}$.

\section{LA DIMENSIÓN COLECTIVA DEL «DERECHO A LA VERDAD»}

Las violaciones de los arts. 2 y 3 del Convenio (entre otros, como se verá) debidas a situaciones de desapariciones forzadas, o cualquier otro tipo (muertes, torturas, malos tratos), aparte de afectar a las víctimas directas o indirectas de tales violaciones, no dejan de tener incidencia sobre intereses más amplios, afectando también a las condiciones de convivencia de la comunidad en su conjunto. Por ello, la obligación de investigar, de hacer públicos los hechos en el origen de esas violaciones, respondería a intereses más allá de los intereses de las víctimas como tales. Ello ha dado lugar a que se plantee, en múltiples contextos, la posible existencia no solo de un derecho de las víctimas a la investigación (como derecho procesal) sino además de un derecho colectivo a la verdad, en cuanto conocimiento general de las circunstancias de la violación grave de derechos humanos con consecuencias sobre la sociedad en general.

La jurisprudencia del Tribunal ha tenido en cuenta en diversas ocasiones la existencia de ese interés colectivo en el descubrimiento y publicidad de la verdad. Ahora bien, y hasta el momento, ese reconocimiento, en supuestos de violaciones de derechos humanos con una repercusión amplia, resulta esencialmente en un reforzamiento del derecho de las víctimas, sin que cobre una dimensión autónoma, ni, con las precisiones que luego se harán, resulte en

11 Janowiec y otros contra Rusia, 55508/07/ y 29520/09, párr. 151: «Sin embargo, el Tribunal considera que el criterio de los "valores del Convenio" no es aplicable a hechos anteriores a la aprobación del Convenio el 4 de diciembre de 1950 porque fue la fecha en que nació como instrumento internacional de protección de los derechos humanos. Por ello, no puede considerarse responsable en virtud del Convenio a un Estado parte por no investigar un delito de derecho internacional, por execrable que sea, si es anterior al Convenio. Pese a que el Tribunal es sensible al argumento de que, incluso actualmente haya países en los que se ha logrado juzgar a responsables de crímenes de guerra que se remontan a la Segunda Guerra Mundial, subraya que hay una diferencia esencial entre poder perseguir a alguien por un grave delito en derecho internacional si las circunstancias lo permiten y la obligación de hacerlo con arreglo al Convenio». Sobre esta cuestión, ver «International and National Courts confronting large-scale Violations of Human Rights. Genocide, Crimes against Humanity and War Crimes. Background paper for the Seminar Opening of the Judicial Year, January 2016», Strasbourg, European Court of Human Rights, 2016. En https://bit.ly/2SVpHIY. 
el establecimiento de nuevos titulares de legitimación procesal para acudir al Tribunal distintos de las víctimas como tales.

Una primera referencia al carácter colectivo de los intereses en juego puede hallarse, en la jurisprudencia del Tribunal, en la sentencia en el caso Asociación 21 de diciembre 1989 y otros contra Rumania, del año 2011. El caso versaba sobre los daños y lesiones causados en la represión de diversas manifestaciones en Rumania, y el Tribunal destacó «la importancia de la investigación para la sociedad rumana, consistente en el derecho de las numerosas víctimas a saber que había ocurrido, incluyendo el derecho a una investigación judicial efectiva y el posible derecho a una compensación» (párr. 142). En forma más directa, la cuestión relativa al derecho a la verdad en su dimensión colectiva se planteó en el mencionado caso Janowiec contra Rusia, por parte de diversas organizaciones no gubernamentales participantes como terceros en el proceso, que pidieron del Tribunal el reconocimiento de un «derecho a la verdad» autónomo, en la línea con los mandatos del derecho internacional. El Tribunal no siguió esta línea, centrándose en su doctrina sobre las obligaciones positivas de tipo procesal en relación con las víctimas; aparte de ello, consideró, respecto a la situación de los familiares, que, en realidad, el tema no versaba sobre «desapariciones», puesto que las muertes en Katyn se habían reconocido ampliamente y se habían convertido en un hecho histórico.

Una consideración más detenida de los aspectos colectivos del «derecho a la verdad» fue la que llevó a cabo el Tribunal (con diversos votos particulares al respecto) en su sentencia en el caso El Masri contra Macedonia, del año 2014. El caso versaba sobre una «entrega extraordinaria» (extraordinary rendition), esto es, sobre la entrega a la Agencia Central de Inteligencia (CIA) norteamericana de un sospechoso de terrorismo por parte de las autoridades de Macedonia, y la subsiguiente detención y maltrato del mismo en Afganistán por miembros de esa Agencia. El Tribunal llega a la conclusión de que se ha producido, por un lado, la violación sustantiva de una serie de derechos relativos a la integridad física del recurrente (art. 3, apreciando el Tribunal que el tratamiento infligido caía bajo la consideración de tortura), a su libertad personal (art. 5), vida privada (art. 8) y acceso a recursos frente a atentados a sus derechos humanos (art. 13); y por otro, que esa violación se ha producido igualmente respecto a los aspectos procedimentales de los arts. 3 y 5 del Convenio. A este respecto, el Tribunal destaca la importancia del conocimiento público de las actividades relativas a la extraordinary rendition por parte de las autoridades de la República de Macedonia y de la Agencia Central de Inteligencia norteamericana. En los reveladores términos del Tribunal, (las negritas son del autor): 
192. El Tribunal no subestima la innegable complejidad de las circunstancias del caso de autos. Así las cosas, aunque en ocasiones, en tal o cual situación concreta, existen obstáculos o dificultades que impiden a una investigación progresar, cuando se trata como en este caso de indagar sobre acusaciones de violaciones graves de los derechos humanos, generalmente la respuesta adecuada de las autoridades es esencial para preservar la confianza del público en el respeto del principio de legalidad y evitar cualquier apariencia de complicidad o tolerancia en relación con los actos ilícitos. Por las mismas razones, el público debe tener un derecho suficiente de seguimiento de la investigación o de sus conclusiones, de forma que se garantice, tanto en teoría como en la práctica, la búsqueda de responsabilidades (Al-Skeini y otros contra Reino Unido [GS], núm. 55721/2007, par. 167, TEDH-2011; Asociación "21 de diciembre 1989" y otros contra Rumanía, núms. 33810/2007 y 18817/2008, par. 135, 24 de mayo de 2011; y Angelova contra Bulgaria, núm. 38361/1997, par. 140, TEDH 2002-IV). Según lo declarado por el Consejo de Europa en sus directrices de 30 de marzo de 2011 sobre la erradicación de la impunidad para las violaciones de los derechos humanos (apartado 105 supra), «[L]os Estados tienen el deber de luchar contra la impunidad, al objeto de hacer justicia a las víctimas, disuadir de la comisión ulterior de violaciones de los derechos humanos y preservar el Estado de Derecho y la confianza de la opinión pública en el sistema judicial» (párrafo 192 de la sentencia).

Como se apuntó, este desarrollo de la posición del Tribunal no dejó de dar lugar a opiniones divergentes dentro del Tribunal, en forma de votos concurrentes (esto es, de acuerdo con el fallo, pero con divergencias en cuanto a sus fundamentos). Por una parte, una opinión concurrente de varios jueces ${ }^{12}$ consideró que el Tribunal debía haber puesto más énfasis en el derecho a la verdad en relación con el art. 13 del Convenio, y que debía haber tratado más en profundidad ese tema en relación con el derecho a recibir información derivado del art. 10 del Convenio. En otra dirección, otra opinión concurrente ${ }^{13}$ estimó que no cabía establecer el derecho a la verdad como algo separado y autónomo de las exigencias procesales de los arts. 3 y 5, y que no cabía tampoco graduar la presencia de un «derecho a la verdad» en función de la mayor o menor publicidad dada a un caso.

La cuestión volvió a plantearse en casos sucesivos. En primer lugar, en los casos Husayn (Abu Zubaydah) contra Polonia y Al Nashiri contra Polonia, ambos de 2014, posteriormente, en las sentencias en los casos Husayn (Abu Zubayda) contra Lituania y Al Nashiri contra Rumania, ambos esta vez del año 2018. En todos estos casos, los recurrentes fueron trasladados a centros de detención de la Agencia Central de Inteligencia en los diversos países en cuestión, con

12 Jueces Tulkens, Spielmann, Sicilianos y Keller.

13 Jueces Casadevall y López Guerra. 
la connivencia de las autoridades competentes, donde fueron torturados mediante diversos procedimientos (las llamadas «técnicas coercitivas», incluyendo los conocidos waterboarding y walling por la agencia norteamericana) durante largo tiempo. Elemento común en todos estos casos fue la declaración por el Tribunal de la violación de derechos de los recurrentes, tanto de orden sustantivo como de orden procesal, en la línea establecida en El Masri. En el caso Al Nashiri, resuelto por la sentencia de 2014, el informador (Rapporteur) especial de Naciones Unidas alegó ante el Tribunal la necesidad de ampliar el concepto de «derecho a la verdad», y extender la titularidad de este derecho más allá de las víctimas a grupos de interés, así como, bajo las previsiones del derecho a la libertad de expresión del art. 10 del Convenio, a los medios de comunicación que debían informar al público. El Tribunal, no obstante, no consideró que el caso pudiera considerarse bajo la óptica del art. 10.

En las sentencias en ambos casos del año 2018 el Tribunal insistió en la vertiente "colectiva» del derecho a la verdad, pero mantuvo su posición contraria a su consideración como un derecho autónomo. Así, en Abu Zubaydah, el Tribunal mantuvo:

El Tribunal pone énfasis en que la importancia y gravedad de los temas en cuestión requieren un escrutinio público particularmente intenso de la investigación. El público de Lituania tiene un interés legítimo en estar informado de los procedimientos penales y su resultado. Por lo tanto, corresponde a las autoridades nacionales asegurar que sin poner en peligro la seguridad nacional, se mantiene un escrutinio público en grado suficiente con respecto a la investigación [...]. El Tribunal además subraya que asegurar la debida responsabilidad de aquellos responsables de haber permitido a la CIA gestionar el lugar de detención «Violet» en territorio lituano es relevante parta mantener la confianza en la adhesión de las autoridades lituanas al estado de derecho. El recurrente y el público tienen derecho a conocer las circunstancias en que se produjeron las operaciones de entrega extraordinaria (extraordinary rendition) en Lituania, y la detención secreta, así como a saber que ocurrió en esos momentos. Una víctima que ha llevado a cabo una alegación verosímil de haber sido sometida a tratamientos contrarios al artículo 3 del Convenio tiene derecho a obtener una exposición adecuada de los sufrimientos infligidos y del papel de aquellos responsables de sus tormentos (párrs. 619 y 620 de la sentencia).

Valga señalar que en gran manera esta posición coincide con la mantenida hasta el momento por la Corte Interamericana, al considerar el derecho a la verdad como un «derecho ligado al derecho a la justicia de las víctimas de violaciones de derechos humanos y a la sociedad en su conjunto, derivado de la obligación de los Estados de emprender acciones judiciales eficaces» (Rodríguez, 2017: 535), por ejemplo en Masacre de el Mozote contra el Salvador y otros muchos casos. 
En todo caso, la Corte Interamericana ha venido a añadir un elemento adicional al derecho a la verdad; las víctimas tendrían derecho a que el resultado de las investigaciones y el reconocimiento de las vulneraciones constatadas se llevaran a cabo públicamente.

\section{LOS PROBLEMAS DE UNA EXTENSIÓN «COLECTIVA» DEL DERECHO A LA VERDAD}

La jurisprudencia citada del Tribunal muestra que este ha preferido, sin ignorar la dimensión colectiva del derecho a la verdad, limitar sus efectos a constituir un elemento de la determinación de la existencia de una investigación adecuada. Lo que plantea la cuestión de si cabe hacer equivaler el derecho a la verdad únicamente al derecho a la investigación destinada a remediar en lo posible la violación producida y el daño causado a las víctimas. El Tribunal, si bien ha apuntado en ocasiones la conveniencia de establecer órganos encargados de llevar a cabo adecuadamente la investigación en estos supuestos (así en Aslakhanova), no ha considerado incluidas en las obligaciones derivadas de la protección de derechos del Convenio la creación de instituciones como «comisiones de la verdad» o la práctica de investigaciones parlamentarias ( $\mathrm{J} a$ nowiec, párr. 143).

Como explicación a esta posición, debe tenerse en cuenta que no es difícil hallar dificultades relevantes que podrían derivar del reconocimiento de un «derecho autónomo» a la verdad distintas de la vertiente procesal de los arts. 2, 3 y 5 . Por una parte, ¿quién sería el titular del derecho? Hablar de un «derecho del público» no resuelve la cuestión, cuando se tiene en cuenta que la efectiva existencia de un derecho deriva de su protección procesal. ¿Quién estaría legitimado para actuar ante los tribunales (y concretamente ante el Tribunal de Estrasburgo) alegando una violación de su «derecho a la verdad»? Una legitimación universal (actio popularis) no deja de presentar evidentes dificultades; y su restricción a grupos de interés plantea el problema de la definición y selección de esos grupos; sobre este punto se harán algunas consideraciones más abajo. Por otra parte, y como se señaló en uno de los votos particulares a $E l$ Masri, no es simple definir qué tipo de violaciones de derechos son de «interés público» justificativo de la aparición de un derecho a la verdad autónomo, y qué tipo no lo son. ¿Debe hacerse ello depender únicamente de la atención de los medios de comunicación sobre determinados casos?

En relación con estos puntos, cabe también tener en cuenta las cuestiones que se plantean en torno a si puede aceptarse un derecho a la verdad que sea solo eso, un derecho al conocimiento de determinadas situaciones, independientemente de sus consecuencias sancionatorias, penales o de otro tipo. 
El carácter autónomo del derecho a la verdad en relación con violaciones de los arts. 2 y 3 supondría la presencia de sujetos legitimados ante los Tribunales, distintos de las víctimas de esas violaciones, y por ello con pretensiones distintas de estas, centradas en la información y el conocimiento más que en el remedio y la reparación. La pregunta es si tiene sentido, desde la misma perspectiva de la justicia, que haya un derecho, en estos casos, a una investigación destinada únicamente a la información pública, y separado y distinto del derecho de las víctimas a una reparación. Aparte, naturalmente, de las dificultades que ello plantearía en la práctica, como se ha visto en supuestos de coexistencia de procedimientos en comisiones de la verdad y, simultáneamente, ante órganos jurisdiccionales sobre los mismos hechos.

Es por eso comprensible que, aún reconociendo, como en el caso también de la Corte Interamericana, la posible utilidad de las comisiones de la verdad como elementos auxiliares, el Tribunal se haya centrado en la vertiente procesal del derecho, con referencia expresa a las víctimas.

Ahora bien, es posible hallar en la jurisprudencia del Tribunal, siguiendo en esto líneas apuntadas por la jurisprudencia de la Corte de San José, una tendencia a reconocer un derecho autónomo a la verdad, pero basado fundamentalmente en el art. 10 del Convenio, esto es, el derecho a la libertad de expresión (y de información), paralelo al reconocido en el art. 13 de la Convención Americana.

\section{VI. ¿UUN DERECHO COLECTIVO DE ACCESO A LA INFORMACIÓN?}

Como se ha señalado, y con ocasión de alegaciones de vulneraciones graves de derechos del Convenio, el Tribunal ha considerado que no resulta de sus mandatos la existencia de un derecho autónomo, separado del derecho de las víctimas, a que se efectúe una investigación adecuada sobre los hechos. El derecho, derivado de las obligaciones positivas de los Estados, a que se lleve a cabo esa investigación se incluiría dentro de la dimensión procesal de los derechos sustantivos alegadamente violados (usualmente referidos a los arts. 2, 3 y 5 del Convenio), y la legitimación para acudir al Tribunal, pertenecería a las víctimas directas o indirectas de esas violaciones. Si el Tribunal tiene en cuenta el interés del público por estar informado de la existencia de esas violaciones y sus consecuencias, ese interés ha sido considerado por el Tribunal como un factor que refuerza la obligación de investigar del Estado, pero no como el origen de un derecho propio de naturaleza colectiva.

En particular, en diversos supuestos (así en El Masri) el Tribunal no ha considerado el caso desde la perspectiva del art. 10, relativo al derecho a recibir o impartir informaciones, por cuanto, 
[...] el Tribunal considera que la cuestión suscitada al amparo de esta disposición se asemeja en el fondo a las quejas relativas al artículo 3, y ya ha sido tratada en el contexto del examen de las mismas (apartado 192 supra). Considera también que el presente caso no plantea ninguna cuestión específica que deba ser analizada en el terreno solamente del artículo 10, ya que esta disposición no es aplicable a los hechos enjuiciados. Por consiguiente, no revela ningún indicio de violación, respecto al demandante, de los derechos y libertades que garantiza este artículo. 265. De ello se infiere que esta queja carece manifiestamente de fundamento en el sentido del artículo 35.3 a) y debe desestimarse en aplicación del artículo 35.4 del Convenio (párrs. 263 y 264 de El Masri).

La cuestión relativa al conocimiento de los hechos mediante la debida investigación se incardinaría así dentro de las obligaciones derivadas del derecho sustantivo vulnerado, de titularidad de las víctimas.

Ahora bien, de la evolución de la jurisprudencia del Tribunal, si bien no resulta del art. 10 del Convenio la existencia de un derecho autónomo de titularidad colectiva a la apertura de una investigación sobre alegadas graves vulneraciones de derechos del Convenio, sí se desprende la existencia de un derecho (de titularidad, podríamos decir, difusa) al acceso a aquellas informaciones con una relevancia pública en poder de las autoridades, informaciones que sin duda incluyen aquellos supuestos de violaciones de derechos humanos que afecten en profundidad a la opinión y que resulten de general interés.

La jurisprudencia del Tribunal ha experimentado un cierto giro en este aspecto en la sentencia de la Gran Sala en el caso Magyar Helsinki Bizottság contra Hungría, del año 2016. En el caso, una organización gubernamental solicitó al Gobierno húngaro la lista de abogados de oficio designados para una serie de casos, lista que constaba en los registros públicos y que le fue denegada por el Gobierno. La organización recurrente ante el Tribunal alegó la violación de su derecho a recibir e impartir información, reconocido en el art. 10 del Convenio.

El Tribunal se plantea si el art. 10 contiene o no un derecho de acceso a la información que el Estado posea sobre una determinada materia. El Tribunal, examinando su jurisprudencia, reconoce que su posición ha sido inicialmente restrictiva: así, en Leander contra Suecia, del año 1987, pudo afirmar que el art. 10 "no confiere a un individuo un derecho de acceso a un registro que contenga información sobre su situación personal, ni implica una obligación del Estado de facilitar esa información al individuo» (párr. 74). Posteriormente, en Guerra y otros contra Italia, del año 1998, el Tribunal insistió en que «la libertad de recibir información no puede interpretarse como imponiendo al Estado, en circunstancias como las del presente caso, obligaciones positivas de recoger y diseminar información por su propia iniciativa» (párr. 53). En general, 
el Tribunal prefería enfocar la cuestión desde la perspectiva del derecho a la vida privada, y no desde la perspectiva del art. 10.

Ahora bien, esta posición inicial se vio matizada en la jurisprudencia posterior, teniendo en cuenta, entre otros factores, si la legislación establecía una obligación de suministrar la información que se solicitase de los registros públicos. El Tribunal pudo así considerar que se producía una violación del art. 10 cuando tal obligación legal existía, y la información en cuestión era un elemento esencial en el ejercicio de la libertad de expresión del recurrente, o bien este ejercitaba una recopilación legítima de información de interés general, con la intención de impartir esa información al público, contribuyendo así a un debate público (así, Guseva contra Bulgaria, de 2015). Partiendo de esta línea evolutiva, el Tribunal, en Magyar Helsinki procede a clarificar su posición.

Y considera que nada le impide interpretar el art. 10 del Convenio en el sentido de incluir un derecho de acceso a la información, siguiendo además las tendencias del derecho internacional. Para el Tribunal, mantener una posición negativa respecto de la inclusión del derecho de acceso a la información en la protección del art. 10 llevaría a situaciones donde el derecho a recibir y suministrar información se vería afectado de tal manera que eliminaría el mismo contenido de la libertad de expresión. En casos en que el acceso a la información sea un instrumento para el derecho del individuo a recibir y suministrar información, su negativa puede suponer una injerencia indebida en ese derecho.

El Tribunal establece una serie de criterios para determinar cuándo existe una obligación del Estado (correlativa a un derecho derivado del art. 10 del Convenio) de permitir el acceso a información en su poder. Por una parte, el propósito de la petición de información: el Tribunal pone el acento sobre si la recopilación de información representa un paso preparatorio importante en actividades periodísticas, o en otras actividades que creen un foro o representen un elemento esencial para un debate público (párr. 158). Y esas consideraciones se aplican también a organizaciones no gubernamentales que asumen una función de vigilancia (social watchdog) pública (párr. 159).

En efecto, el Tribunal concede especial importancia al papel del demandante de información, subrayando la importancia de la prensa o las actividades de entidades no gubernamentales: «El Tribunal ha reconocido que las funciones de crear varias plataformas de debate público no se limitan a la prensa sino que también pueden llevarse a cabo por (entre otros) organizaciones no gubernamentales, cuya actuación es un elemento esencial del debate público informado» (párr. 166). Y ese nivel de protección puede extenderse también a investigadores académicos o autores de estudio o literatura sobre temas de atención pública. Adicionalmente, atendiendo al papel de internet, «la 
función de los bloggers y los usuarios populares de los medios sociales puede asimilarse a la de los vigilantes públicos (public watchdogs)» en lo que se refiere a la protección del art. 10 (par. 168). El Tribunal precisa en todo caso que el derecho de acceso a la información se refiere a aquella en manos del Estado que esté inmediatamente disponible (ready and available) y no necesite de una actuación de recopilación por las autoridades.

Cabe considerar que la doctrina sentada en Magyar Helsinki supone un cierto reconocimiento de un «derecho a la verdad» de titularidad pública, ciertamente con algunas matizaciones. Por una parte, y desde una perspectiva positiva, por cuanto informaciones sobre violaciones graves de derechos del Convenio, particularmente relativas a muertes, torturas, secuestros o desapariciones con implicación de los poderes públicos representan sin duda materias de interés general cubiertas por la protección del derecho a recibir e impartir información del art. 10. Y como consecuencia, la legitimación para iniciar acciones procesales al respecto, en supuestos de ocultación de los hechos por las autoridades, se amplía considerablemente, al no encontrarse limitada a los titulares de las violaciones de los derechos sustantivos (de los arts. 2, 3, 5 o cualquier otro) de que se trate. Esa titularidad para la invocación del art. 10 se extenderá ya, más allá de las víctimas (en cuyo caso, como se vio, el derecho a la verdad se integra dentro de la dimensión procesal de los derechos alegadamente violados), a individuos u organizaciones que cumplan una función de «vigilancia social» según la enumeración que se realiza en Magyar Helsinki.

Ciertamente, ese «derecho a la verdad» se ve limitado en cuanto se refiere a informaciones ya existentes en las instituciones del Estado, sin que incluya la obligación de una actividad investigadora de este; se trataría de un derecho a la información, y no de un «derecho a una investigación». Pero sin duda, y en cuanto, de una forma u otra, exista constancia en las instituciones y archivos estatales de la práctica de actividades en violación de los derechos humanos, no podrá denegarse el acceso a la información existente a los representantes de esa «vigilancia social». Desde esta perspectiva sí puede hablarse de un «derecho colectivo" a la verdad, cuyo ejercicio se encomienda a sujetos especialmente cualificados.

Este derecho tiene además importantes consecuencias; el acceso a los archivos públicos solo será posible si tales archivos efectivamente existen. Por ello, un corolario del derecho a la información es la obligación de mantener esos archivos y, desde luego, no destruirlos; valga recordar que una práctica frecuente en procesos de transición es la destrucción de los registros que se consideran comprometedores para las autoridades del momento. Tal actuación resultará ilegítima desde la perspectiva de resoluciones internacionales en materia de derechos humanos. Particularmente relevante al respecto resulta, 
por ejemplo, el informe del Consejo de Derechos Humanos del año 2009 sobre conservación de $\operatorname{archivos}^{14}$.

Valga señalar que la posición del Tribunal Europeo en Magyar Helsin$k i$ ha sido ya anticipada en la jurisprudencia de la Corte Interamericana de Derechos Humanos. En el caso Gomes Lund y otros contra Brasil de 2010, la Corte puso el acento en el derecho a la información derivado del art. 13 del Convenio para fundamentar la obligación de las autoridades de suministrar la información requerida sobre violación de derechos humanos; en un paso más avanzado, la sentencia en el caso Gudiel Alvarez y otros contra Guatemala vino a condenar a este país por no haber suministrado la información obrante en su poder a la comisión de la verdad actuante.

Desde esta perspectiva, cabe inferir una serie de consecuencias derivadas de este (limitado) «derecho a la verdad» que resulta de las obligaciones positivas del Estado. Por un lado, el deber de las autoridades de conservar aquellos archivos que versen sobre actuaciones de los poderes públicos con incidencia en el respeto a los derechos humanos: la (frecuente) destrucción de documentación en situaciones de transición a la democracia supone una práctica que imposibilita no solo la debida reparación a las víctimas, sino también, desde una perspectiva general, el conocimiento por la sociedad de materias de extrema importancia para la convivencia. A ello se une el deber de permitir el acceso a los archivos existentes, tanto a los afectados como a los medios de comunicación y a aquellos sujetos que cumplen un papel relevante en los procesos de información y conocimiento por parte del público. Desde esta perspectiva, y aun cuando esa labor de información y divulgación no tenga inmediatos efectos jurídicos, los poderes públicos no deben oponerse a ella; y aún más allá, y como se apuntó por la Corte Interamericana en Gudiel, la colaboración por parte de esos poderes puede considerarse en determinados supuestos (así al respecto de las comisiones de la verdad), obligatoria.

\section{Bibliografía}

Chersinova, O. (2016). Right to truth in the case law of the European Court of Human Rights. En L. Early et al. (dirs.). The right to life (pp. 145-160). Osterwijk Wolf Legal Publishers.

De Prada Solaesa, R. (2015). Justicia transicional en Colombia. Jueces para la Democracia, $85,135-148$.

14 Consejo de Derechos Humanos. El derecho a la verdad. Informe de la Oficina del Alto Comisionado de las Naciones Unidas parta los Derechos Humanos, Doc. A/HRC/12/19, 21 de agosto de 2009. 
Brems, E. (2011). Transitional Justice in the Case Law of the European Court of Human Rights. International Journal of Transitional Justice, 5 (2), 282-303. Disponible en: https://doi.org/10.1093/ijtj/ijr010.

Fornasari, G. (2017). Justicia de transición: una visión de conjunto con la lente del penalista. Teoría y Derecho. Revista de Pensamiento Jurídico, 21, 154-185.

Keller, H. y Chersinova, O. (2012). Disappearance cases before the European Court of Human Rights and the UN Human Rights Committee: Convergences and divergences. Human Rights Law Journal, 32, 237-249.

López Ulla, J. M. (2013). El derecho a la verdad en la jurisprudencia del Tribunal Europeo de Derechos Humanos. Persona y Derecho, 69, 127-164.

Rodríguez, J. (2017). Derecho a la verdad y Derecho internacional en relación con graves violaciones de los derechos humanos. Madrid: Biblioteca de Derechos Humanos Berg Institute.

Sweeney, J. A. (2018). The elusive right to truth in transitional human rights jurisprudence. International and Comparative Law Quarterly, 67, 353-387. Disponible en: https://doi.org/10.1017/S0020589317000586. 